\title{
O que mudar na educação? - Representações sociais de alunos de Pedagogia
}

(c) (1) (8)

\author{
What change in education? - Representations \\ of students of education
}

\begin{abstract}
Bruna Luise da Silva Sant'Ana ${ }^{[a]}$, Daniela Barros da Silva Freire Andrade ${ }^{[b]}$
[a] Mestre em Educação pelo Programa de Pós-Graduação em Educação da Universidade Federal de Mato Grosso (PPGE/UFMT), Cuiabá, MG - Brasil, e-mail: brunaluise@gmail.com

[b] Professora Doutora, orientadora do presente estudo, vinculada ao Programa de Pós-Graduação em Educação da Universidade Federal de Mato Grosso (PPGE/UFMT), Cuiabá, MG - Brasil, e-mail: freire.d@terra.com.br
\end{abstract}

\section{Resumo}

Este estudo objetivou investigar as representações sociais de acadêmicos de Pedagogia da Universidade Federal de Mato Grosso, sobre mudanças na Educação. A pesquisa baseou-se na Teoria das Representações Sociais (MOSCOVICl, 1978; JODELET, 2005), bem como nos estudos sobre mudanças no contexto educacional. Foram realizadas 40 entrevistas semiestruturadas, distribuídas nas quatro séries da graduação. O corpus pelas entrevistas foi processado no software Alceste, sendo utilizada sua análise padrão e também a análise tri-croisé referente à variável $t$. Observou-se que as representações sociais dos acadêmicos em Pedagogia da 
UFMT, sobre mudanças na Educação, fazem um movimento entre o engajamento individual diante da sua formação e sobre as necessidades de mudanças na Educação, transformando-se ao longo do curso em uma queixa imobilizadora, que parece substituir a atitude de implicação diante das mudanças.

Palavras-chave: Representações sociais. Educação. Mudanças. Acadêmicos de Pedagogia.

\section{Abstract}

This study aimed at investigating the social representations about changes in Education constructed by the academics of the Pedagogy course at the Federal University of Mato Grosso. The research was based on the Theory of Social Representations (MOSCOVICI, 1978; JODELET, 2005), as well as studies on changes in the educational context. A number of forty semi structuralized interviews were applied to the students of the four series of the course. The verbal material obtained from the interviews was processed by the software Alceste. The standard analyses of the software added to the tri-croise analyses of the variable year were done. It was observed that the social representations about changes in the Education constructed by the Pedagogy students from the UFMT make a movement between their individual enrollment concerning qualification and their necessities of changes in Education. The students' social representations have been changing throughout the Pedagogy course into an immobilizing complaint that seems to replace their concerned attitudes facing the educational changes.

Keywords: Social representations. Education. Changes. Academics of Pedagogy.

\section{Introdução}

O presente estudo surgiu a partir de discussões do Grupo de Pesquisa Educação e Psicologia (GPEP) em torno do trabalho docente, sendo realizado entre 2007 e 2008, com ênfase nas representações sociais de acadêmicos em Pedagogia da Universidade Federal de Mato Grosso (UFMT) sobre mudanças na educação.

Rev. Diálogo Educ., Curitiba, v. 11, n. 33, p. 375-396, maio/ago. 2011 
Tal temática mostrou-se pertinente, dado que é recorrente para a busca por mudanças na educação, sob a forma de inovações educacionais que geralmente são imposições governamentais (MORGADO, 2005), ou pela busca de melhores condições de trabalho pelo professor, discurso evidente especialmente em sindicatos da classe.

Foram escolhidos os alunos de Pedagogia por se ter observado em estudos anteriores, no âmbito do GPEP (SILVA, 2008; BENTO-GUTH, 2008; CÂNDIDO; BATISTA, 2008), certa consensualidade nas representações sociais dos professores e alunos de licenciaturas sobre a ausência de discursos a respeito da articulação coletiva entre a classe docente e pouca implicação em processos de mudança. Além disso, o fato de as discussões sobre mudanças serem emergentes na literatura educacional traz novamente a relevância de tal objeto de representação para os futuros docentes.

O referencial teórico norteador desta investigação é a Teoria das Representações Sociais (TRS), tendo como autores fundamentais Serge Moscovici (1978) e Denise Jodelet (2001).

Quanto ao conceito de representações sociais (RS), Jodelet (2001, p. 22) explica que é:

uma forma de conhecimento socialmente elaborada e partilhada, com um objetivo prático, e que contribui para a construção de uma realidade comum a um conjunto social. Igualmente designada como saber do senso comum ou ainda saber ingênuo, natural, esta forma de conhecimento é diferenciada, entre outras do conhecimento científico.

$\mathrm{Na}$ Teoria das Representações Sociais, as mudanças aparecem como fatores extremamente relevantes na produção de RS. A própria proposição de Moscovici (1978) em torno do conceito de RS se dá em função de que, na modernidade, as mudanças sociais são mais intensas, fazendo com que a sociedade em geral crie teorias coletivas de significação do estranho, do novo, do incógnito.

Diante de transformações que rompam o círculo da estabilidade social, o grupo mobiliza-se cognitiva e afetivamente para nomear e dar sentido à novidade, aproximando-a de sua realidade e destituindo-a 
de ameaças. Arruda (2000, p. 244) afirma, a esse respeito, que "qualquer proposição de mudança tenderá a introduzir novos objetos de elaboração (que podem ser novas práticas, novos mitos ou novas idéias) ou novas elaborações de velhos objetos".

Dentre as funções das representações sociais para os grupos, situam-se: formação de condutas e orientação das comunicações sociais. É a partir dessas teorias que os grupos, por meio de conversas, orientam suas ações e compreendem a realidade (MOSCOVICI, 1978).

Concomitantemente a essas funções, as RS proporcionam ao grupo o processo de identificação, haja vista que é por meio delas que os indivíduos reconhecem, em seus pares, signos e práticas sociais próprias e protegem o grupo da tensão gerada por um elemento estranho (JODELET, 2001).

No ato de representar, haverá modificações no que foi dito anteriormente, mediante a comunicação. Dessa maneira, pode-se perceber que a representação ultrapassa a reprodução da realidade. O processo de defasagem está implicado três condições que refletem na construção das representações sociais, sendo a primeira delas a dispersão da informação, que consiste em uma defasagem constitutiva (MOSCOVICI, 1978). Nesse caso, o acesso a informações que o grupo possui, seja por interesse ou por obstáculos de comunicação, interfere sobre o modo pelo qual o objeto de representação é apreendido.

Outra condição que afeta a formação das RS é a focalização, que diz respeito ao grau de implicação e à distância do grupo em relação ao objeto social. Segundo Moscovici (1978, p. 252), "o esforço essencial do sujeito não é para compreender essa teoria no âmbito que lhe é próprio, mas para destacar e pôr em relevo perspectivas que se harmonizem com as suas orientações profundas".

Por último, há ainda a pressão à inferência, na qual é exigido do indivíduo ou grupo social que responda sempre, tome posições e seja capaz de agir nas mais diversas situações, fazendo com que ligue premissas a conclusões, sem relações diretas.

Assim, diante de uma situação estranha, que desestabiliza as certezas de um grupo, são desencadeados dois processos formadores das RS 
denominados ancoragem e objetivação (MOSCOVICI, 2003). Tais processos são inseparáveis, ocorrendo simultaneamente na criação de representações sociais. A ancoragem é a parte simbólica e a objetivação relaciona-se à parte figurativa. Ao representar, por conseguinte, os grupos sociais destacam uma figura e a carregam de sentido (MOSCOVICI, 1978).

$\mathrm{O}$ mecanismo de ancoragem equivale a aproximar aquilo que é estranho em um sistema de significados já presente na vida do grupo. Busca-se, pois, adequar o elemento novo e desconhecido em categorias familiares. Simultaneamente, a objetivação busca uma estrutura imagética para a representação, a fim de tornar os elementos estranhos acessíveis à vida cotidiana. Desse modo, liga-se uma ideia a uma imagem.

\section{Metodologia}

Foram entrevistados 40 alunos do curso de Pedagogia da UFMT, sendo 20 alunos do período matutino e os demais no período vespertino, distribuídos de modo equitativo do $1^{\circ}$ ao $4^{\circ}$ ano da graduação. No roteiro de entrevistas, foram delineadas duas etapas: primeiramente foram direcionadas perguntas a respeito de mudanças no curso de Pedagogia e, posteriormente, as indagações se relacionavam às mudanças na educação e na vida do professor.

Buscou-se nesse duplo direcionamento verificar o grau de envolvimento dos acadêmicos com as mudanças, assim como as diferenças e semelhanças nas representações partilhadas para as duas situações.

As entrevistas foram gravadas em áudio, com o devido consentimento dos sujeitos, e depois transcritas e formatadas para o processamento, por intermédio do software Alceste, que possibilitou a categorização dos discursos mediante classes de palavras características. Além dessa análise padrão, o programa oferece uma ferramenta, denominada tri-croisé, que permite ao pesquisador a diferenciação de discursos segundo variáveis selecionadas pelo pesquisador. 
Os dados aqui apresentados referem-se à análise tri-croisé segundo a variável ano, a fim de obter as diferenças e semelhanças entre as representações sociais dos alunos de Pedagogia dos diferentes anos.

\section{Análise e discussão}

Ao isolar a variável ano, o software Alceste processou o texto e gerou quatro classes, cada uma sendo constituída pelos discursos de uma série específica. Desse modo, ao isolar a variável ano, o software processou o texto e gerou quatro classes, cada uma sendo constituída pelos discursos de uma série específica. A relação entre as classes se fez segundo o dendrograma subsequente (Figura 1 ).

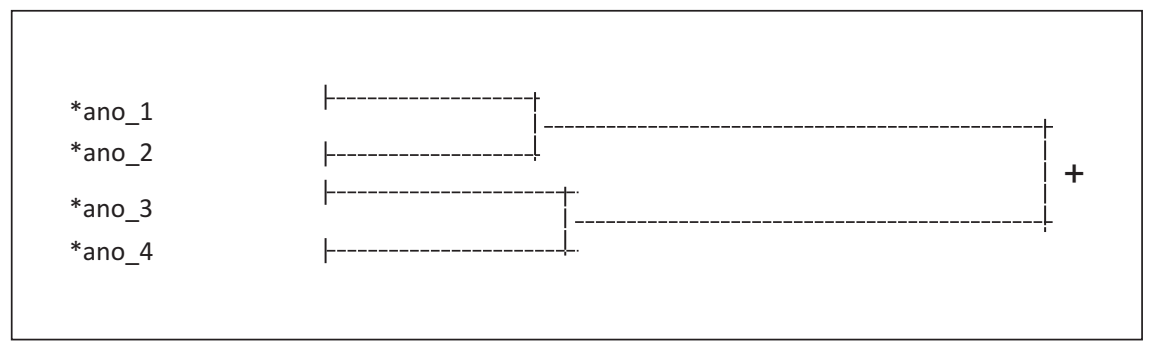

Figura 1 - Dendrograma gerado pelo tri-croisé a partir da variável ano Fonte: Dados da pesquisa.

Optou-se por expor detalhadamente o conteúdo de cada classe a partir do primeiro ano. Para construir as listas de palavras características, foram delimitados pontos de corte por $\chi^{2}$, que variaram de acordo com a especificidade das classes.

A série inicial do curso de Pedagogia obteve o total de 355 UCEs analisadas, constituindo $18,28 \%$ do discurso total, tendo como ponto de corte as palavras com $\chi^{2}$ acima de 13,00 (Tabela 1). 
Tabela 1 - Palavras representativas da classe 10 ano, em ordem decrescente de $\chi^{2}$

\begin{tabular}{lrrrc}
\hline Palavras e formas associadas & FPC & FPT & PR & $\chi^{\mathbf{2}}$ \\
\hline Profissionais, profissional & 40 & 75 & 53,33 & 64,17 \\
Método, métodos & 13 & 21 & 61,9 & 27,05 \\
Maneira & 24 & 55 & 43,64 & 24,36 \\
Depende & 28 & 70 & 40 & 22,93 \\
Algo & 38 & 109 & 34,86 & 21,26 \\
Melhor, melhora, melhoras, melhore, melhores & 54 & 175 & 30,86 & 20,37 \\
Tipo, tipos & 20 & 46 & 43,48 & 20,03 \\
Academia, acadêmica, acadêmico, acadêmicos & 9 & 14 & 64,29 & 19,98 \\
Aquilo & 35 & 100 & 35 & 19,73 \\
Conversar & 8 & 12 & 66,67 & 18,92 \\
Incômodo & 4 & 4 & 100 & 17,92 \\
Incomodar & 4 & 4 & 100 & 17,92 \\
Seria & 29 & 81 & 35,8 & 17,37 \\
Mudança, mudanças & 185 & 828 & 22,34 & 15,95 \\
For, fora & 32 & 98 & 32,65 & 14,27 \\
Humano & 6 & 9 & 66,67 & 14,17 \\
Área, áreas & 19 & 49 & 38,78 & 14,14 \\
Corre, correr & 13 & 29 & 44,83 & 13,89 \\
Inovar & 3 & 3 & 100 & 13,43 \\
Moral & 3 & 3 & 100 & 13,43 \\
Reunir & 5 & 7 & 71,43 & 13,28 \\
Diferenciada & 5 & 7 & 71,43 & 13,28 \\
Qualificação & 5 & 7 & 71,43 & 13,28 \\
\hline & & & & \\
\hline
\end{tabular}

Fonte: Dados da pesquisa.

Por meio das palavras características dessa classe, observou-se que os assuntos mais marcantes dos alunos do primeiro ano dizem respeito ao envolvimento pessoal diante de mudanças e dos ganhos daí 
advindos. De modo geral, eles acreditam na mudança como aquilo que é novo, diferente, o qual deve acontecer quando algo não está bom. Assim, creem na mudança como algo que possibilita uma evolução.

Eu penso em mudança como crescimento. Se for para mudar que seja para crescer, para melhor, seja na vida profissional ou na vida pessoal (Suj. 1, $1^{\circ}$ ano matutino, sexo feminino).

Quando eu penso em mudança eu penso em algo diferente, algo novo. É o que eu penso em relação a isso. Quando a gente está falando em mudança é algo relativo à transformação, algo novo (Suj. $9,1^{\circ}$ ano matutino, sexo feminino).

Na posição dos alunos do primeiro ano, mudar é algo novo, sem relação com o passado, sempre relacionado com o crescimento, sem expectativas negativas. Eles destacam, ainda, as mudanças como situações em que se têm muitas coisas a ganhar, especialmente experiência e conhecimento.

Eu acho que ele ganha muito, ganha mais conhecimento, um reconhecimento de outros profissionais, apesar de que tem uns que veem com bons olhos e tem outros que não, mas eu acho que, de uma maneira geral, ele está querendo um reconhecimento. Quando ele trabalha, ele quer o reconhecimento daquilo, do trabalho que ele está fazendo, porque todo mundo que trabalha quer o reconhecimento de alguém, dos pais (Suj. $27,1^{\circ}$ ano vespertino, sexo feminino).

Além do conhecimento adquirido pelo investimento em mudanças, a fala citada mostra que caso o professor se posicione favoravelmente às mudanças, ganha reconhecimento social. Esse discurso parece ter relação com o momento de descoberta da mudança com valorização social, vivenciado por eles por conta da aprovação recente no vestibular.

Desse modo, os acadêmicos do primeiro ano revelam que, para que haja mudanças, tanto para o professor na escola pública quanto para si próprios, é preciso o engajamento pessoal, muitas vezes dito por expressões como correr atrás. 
Não sabia o que era aquilo, eu adquiri muita experiência, de correr atrás. Eu pensava que era outra coisa, eu achava que era uma coisa totalmente diferente a faculdade em si (Suj. 28, $1^{\circ}$ ano vespertino, sexo feminino).

Assim, para esse grupo, o envolvimento individual e o desejo implicado com a expressão correr atrás parecem uma fórmula infalível, tanto na universidade como para a busca por metodologias diferenciadas na educação básica.

Portanto, observa-se que esse grupo específico da Pedagogia pouco se pronuncia a respeito de articulação coletiva em situações de mudanças. É possível levantar a hipótese de que, diante de novos conhecimentos e novas relações estabelecidas com o mundo universitário, os alunos tenham entrado em um estado de intensas transformações de seus grupos de referência, assim como de suas próprias características.

Pode-se notar que os discursos dos licenciandos são diferenciados no tocante ao posicionamento diante das mudanças, sob três perspectivas:

1) a mudança é algo que deve se buscar para melhorar, evoluir;

2) os ganhos como experiência e conhecimento parecem amenizar os riscos implicados com mudanças;

3) a mudança é algo que deve se desejar, e ainda buscar, requerendo um engajamento individual.

O discurso dos alunos do segundo ano apresentou-se em 455 UCEs analisadas, compondo $23,47 \%$ do total dos discursos. Para a análise dessa classe, levou-se em consideração as palavras com $\chi^{2}$ acima de 13,00 (Tabela 2).

De modo geral, as palavras apresentadas na Tabela 2 parecem retratar o que os acadêmicos do segundo ano pensam sobre a tomada de posições diante das mudanças, especialmente a respeito dos alunos, termo que aparece na classe como um dos vocábulos de maior frequência. 
Tabela 2 - Palavras representativas da classe $2^{\circ}$ ano, em ordem decrescente de $\chi^{2}$

\begin{tabular}{lrrrl}
\hline Palavras e formas associadas & FPC & FPT & PR & $\chi^{\mathbf{2}}$ \\
\hline Realmente & 46 & 80 & 57,5 & 53,99 \\
Maioria & 35 & 64 & 54,69 & 36,04 \\
Acredito & 55 & 131 & 41,98 & 26,96 \\
Ocorrem & 8 & 9 & 88,89 & 21,6 \\
Caso, casos & 36 & 82 & 43,9 & 20 \\
Respeito & 10 & 14 & 71,43 & 18,11 \\
Realidade & 28 & 61 & 45,9 & 17,73 \\
Possa & 12 & 19 & 63,16 & 16,88 \\
Deseja, deseje & 5 & 5 & 100 & 16,38 \\
Propondo & 5 & 5 & 100 & 16,38 \\
Aluno, alunos & 130 & 423 & 30,73 & 16,08 \\
Certa & 29 & 66 & 43,94 & 16,02 \\
Posição & 6 & 7 & 85,71 & 15,19 \\
Papel & 11 & 18 & 61,11 & 14,38 \\
Próprio, próprios & 22 & 48 & 45,83 & 13,77 \\
Mercado & 10 & 16 & 62,5 & 13,73 \\
Sentem & 9 & 14 & 64,29 & 13,12 \\
Omisso & 4 & 4 & 100 & 13,1 \\
Desejar & 4 & 4 & 100 & 13,1 \\
Resolver & 4 & 4 & 100 & 13,1 \\
\hline
\end{tabular}

Fonte: Dados da pesquisa.

De modo semelhante aos alunos do primeiro ano, os licenciandos situados na segunda série do curso destacam o engajamento individual em situações de mudanças, apresentando mais elementos da prática, o que demonstra maior contato com as discussões acerca da educação. Entretanto, ao se posicionarem diante das mudanças no curso de 
Pedagogia, assinalam a necessidade de articulação entre seus pares para que consigam as modificações que levantam como imprescindíveis.

De certa forma acho que são os próprios alunos porque se eles se sentem insatisfeitos com a metodologia do curso e de alguma forma eles vão demonstrar isso, ou através do dossiê ou vendo o mercado de trabalho, que o curso não está encaixando no mercado de trabalho (Suj. 8, $2^{\circ}$ ano matutino, sexo feminino).

Então isso faz com que os alunos tomem uma posição em relação a isso, para que isso mude. Então, tanto da estrutura do curso mesmo, como da atitude dos alunos dentro da sala de aula (Suj. 11, $2^{\circ}$ ano matutino, sexo feminino).

Os alunos reconhecem, pois, seu papel na busca por mudanças, mas também sofrem com os riscos das consequências desse envolvimento. Os licenciandos em Pedagogia, do segundo ano, parecem mostrar maior implicação em relação às decisões coletivas do que aqueles que estão no primeiro ano.

Tem aqueles alunos que se sentem um pouco reprimidos, isso, ou com medo de posteriormente ocorrer uma retaliação, que já ocorreu com os alunos. Então eles procuram um meio termo, no caso, eles procuram a gente quando o problema se torna um pouco complicado de se resolver (Suj. $11,2^{\circ}$ ano matutino, sexo feminino).

A fala anterior é de uma aluna que faz parte do Centro Acadêmico de Pedagogia (CAP), que lida com as demandas por mudanças vindas de seus pares. Assim, conforme o depoimento da licencianda, os alunos que não se sentem confortáveis em se implicar com situações de mudanças, procuram o CAP para mediar sua relação com os superiores da instituição. Desse modo, os licenciandos em Pedagogia matriculados no segundo ano parecem mostrar maior implicação em relação às decisões coletivas do que aqueles que estão no primeiro ano. Esses alunos anunciam, portanto, uma postura ativa dentro na universidade. 
Há ainda nesse grupo discursos sobre a posição do aluno e do professor na educação básica. Vale lembrar que os alunos não são vistos como atores de sua aprendizagem nesse contexto, mas sim com certa passividade na participação escolar. O papel do professor é caracterizado com maior engajamento diante das mudanças na escola.

Acho que, nesse caso, os professores. Porque já que eles estão ali todo o dia com os alunos, eles conseguem ver realmente o que precisa ser mudado (Suj. 5 , $2^{\circ}$ ano matutino, sexo masculino).

Portanto, a fala anterior parece colocar o aluno em outra posição na escola. Lá o aprendiz é observado pelo professor e, de acordo com as demandas discentes observadas pelos docentes, os métodos poderão mudar ou não.

Ao situarem o professor como agente da mudança na escola, os licenciandos não ignoram as imposições provindas dos órgãos reguladores da Educação e ainda falam delas como obstáculos ao trabalho docente que devem ser superados.

Tem uns que chegam lá, dá a aula dele, dá o conteúdo que foi imposto e pronto: aprendeu, aprendeu, se não aprendeu tudo bem. Eu já dei a minha aula hoje já está bom. [...] Então de alguma forma ele vai driblar um pouco isso dentro da sala de aula, mas se ele tiver realmente integrado com aquela ideia de ser um educador competente, um educador que realmente busque uma educação melhor, um ensino melhor (Suj. 8, $2^{\circ}$ ano matutino, sexo feminino).

O professor, conforme exposto pela fala anterior, deve, idealmente, sair da posição meramente protocolar e ganhar um exercício profissional autêntico, engajado e eficiente. A mudança em que o professor deverá ser protagonista relaciona-se à sua ação fim, junto com seu aluno, sem esperar auxílio externo.

Desse modo, os acadêmicos do segundo ano parecem enfatizar aspectos identitários de seu grupo, em que tanto na escola, na condição de futuro professor, como na universidade, no papel de acadêmicos, posicionam-se de forma engajada diante da ideia de mudança. 
No tocante ao terceiro ano, observa-se que o discurso desse grupo organizou-se em torno de 534 UCEs, o que constitui a porcentagem de $27,50 \%$ do corpus analisado.

Nesse grupo, os temas discursivos giraram em torno das expectativas em relação à formação, sobre o profissional pedagogo, o curso de Pedagogia e, ainda, o que lhes é reservado posteriormente à graduação. As palavras selecionadas foram aquelas com $\chi^{2}$ acima de 13,00 (Tabela 3).

De modo geral, os acadêmicos do terceiro ano de Pedagogia falam a respeito de sua formação na UFMT e das transformações ocorridas em sua faculdade, dos ganhos e perdas inclusos nela e, ainda, sobre as mudanças que esperam que ela possibilite no futuro, conforme assinala o discurso a seguir:

aqui da UFMT vai aumentar um ano, e também uma das propostas que eles apresentaram foi da educação infantil, creio que seja essa que está na ementa e dá educação de jovens e adultos, que eu não tenho habilitação e que vai ter posteriormente. Em outras faculdades particulares, o curso de Pedagogia você faz em três anos, da UFMT aumentou para cinco, irá aumentar para cinco anos, cobra mais do profissional (Suj. $30,3^{\circ}$ ano vespertino, sexo feminino).

Eu, por exemplo, eu quero muito fazer meu mestrado, assim que eu acabar a universidade, fazer meu doutorado, quero aproveitar todo o leque que meu curso oferece. Ou então eu posso estar me contradizendo porque, já que eu formo opiniões, o pedagogo está vendo que a rede estadual não está lá essas coisas para dar aula, o pessoal que vem das particulares ou que vem de outras universidades acabam dando aula lá, então eles já estão vendo pelo menos esse lado, a questão salarial. A gente não vê um filho de pedagogo estudando dentro de uma escola pública, não tem (Suj. 25, $3^{\circ}$ ano matutino, sexo feminino).

Na primeira fala, a aluna parece anunciar que os profissionais formados nessa universidade saem melhor preparados do que os que provem de instituições privadas, e que aqueles que se graduarão no futuro serão professores mais cobrados e gabaritados, por se formarem em cinco 
Tabela 3 - Palavras representativas da classe 3 ano, em ordem decrescente de $\chi^{2}$

\begin{tabular}{lrrrc}
\hline Palavras e formas associadas & FPC & FPT & PR & $\boldsymbol{x}^{\mathbf{2}}$ \\
\hline Creio & 45 & 53 & 84,91 & 90,07 \\
Vejo & 65 & 114 & 57,02 & 52,94 \\
UFMT & 16 & 19 & 84,21 & 30,96 \\
Foram & 21 & 30 & 70 & 27,61 \\
Rede & 16 & 23 & 69,57 & 20,66 \\
Geografia & 9 & 10 & 90 & 19,7 \\
Campo & 13 & 18 & 72,22 & 18,23 \\
Jovens & 9 & 11 & 81,82 & 16,37 \\
Povo & 6 & 6 & 100 & 15,87 \\
Igreja & 6 & 6 & 100 & 15,87 \\
Estranhamento & 6 & 6 & 100 & 15,87 \\
Estado, estados & 15 & 24 & 62,5 & 14,93 \\
Marido & 7 & 8 & 87,5 & 14,51 \\
Total & 7 & 8 & 87,5 & 14,51 \\
Cara, caras & 8 & 10 & 80 & 13,9 \\
Mulher, mulheres & 8 & 10 & 80 & 13,9 \\
Cinco & 10 & 14 & 71,43 & 13,65 \\
Estadual & 10 & 14 & 71,43 & 13,65 \\
Assim & 5 & 383 & 34,99 & 13,42 \\
Militar & 5 & 5 & 100 & 13,22 \\
Inesperado & 5 & 100 & 13,22 \\
\hline & & 5 & & \\
\hline
\end{tabular}

Fonte: Dados da pesquisa.

anos. No segundo discurso, a acadêmica expõe as possibilidades de mudanças que enxerga em seu futuro, por meio da qualificação profissional, assim como o conflito em atuar na educação básica, dado que essa poderia ser uma posição menos valorizada. Tais estudantes falam, também, dos

Rev. Diálogo Educ., Curitiba, v. 11, n. 33, p. 375-396, maio/ago. 2011 
pedagogos que estão em exercício e do tempo necessário para que mudanças desencadeadas pelos futuros profissionais aconteçam.

Eu, novamente, puxando aí a questão da experiência pela idade, eu tenho parentes, eu tenho irmãs pedagogas já com pós-graduação e você vê a luta delas e realmente o campo da docência no Mato Grosso foi muito beneficiado até em termos salariais (Suj. 24, $3^{\circ}$ ano matutino, sexo masculino).

Tem um período de tempo para essa transformação, para essa mudança ocorrer, eu creio que seja assim. As práticas continuam, porque muitos que estão na rede não tiveram uma educação que a gente teve, o curso de Pedagogia passou por várias modificações, igual a mim, vou estudar quatro anos e tem aluno que vai estudar cinco (Suj. $30,3^{\circ}$ ano vespertino, sexo feminino).

A primeira fala refere-se às mudanças acontecidas na vida do pedagogo atuante e considera que houve benefícios em termos salariais, ocasionados pela luta desses profissionais. A segunda licencianda parece desconhecer mudanças na educação da atualidade, compreendendo que as transformações somente irão ocorrer quando os futuros pedagogos, com essa nova formação, entrarem nas redes de ensino.

Dessa forma, os alunos de Pedagogia, do terceiro ano da graduação, demonstram ter como representações específicas as expectativas em relação à formação, as mudanças anunciadas em Pedagogia, as possibilidades de transformação enquanto futuros pedagogos e, ainda, a continuidade nos estudos. Nesse sentido, pode-se dizer que o terceiro ano analisa mudanças pontuais e concretas da sua formação, que afetam o nível pessoal e profissional.

As falas dos alunos do quarto ano compuseram 598 UCEs, o que totalizou 30,79\% do corpus. Para a seleção das palavras características, utilizou-se como ponto de corte o $\chi^{2}$ de 12,00.

Pode-se observar, pelas palavras expostas na Tabela 4, que os assuntos tratados por esse grupo de licenciandos referem-se às discussões acerca dos envolvidos e responsáveis por mudanças na educação. Além disso, os estudantes entrevistados desvelam o que encontraram na 
Tabela 4 - Palavras representativas da classe 4ㅇan ano, em ordem decrescente de $\chi^{2}$

\begin{tabular}{lrrrc}
\hline Palavras e formas associadas & FPC & FPT & PR & $\chi^{\mathbf{2}}$ \\
\hline Questão & 86 & 179 & 48,04 & 27,54 \\
Preciso & 16 & 20 & 80 & 22,96 \\
Proposta, propostas & 20 & 28 & 71,43 & 22,01 \\
Discussões & 10 & 11 & 90,91 & 18,76 \\
Caderno, cadernos & 8 & 8 & 100 & 18,05 \\
Envolvido, envolvidos & 11 & 13 & 84,62 & 17,79 \\
Turma, turmas & 25 & 42 & 59,52 & 16,63 \\
Agora & 73 & 163 & 44,79 & 16,35 \\
Participei & 7 & 7 & 100 & 15,79 \\
Prova, provas & 10 & 12 & 83,33 & 15,64 \\
Estágio, estágios & 14 & 20 & 70 & 14,58 \\
Você, vocês & 186 & 495 & 37,58 & 14,34 \\
Alterar & 8 & 9 & 88,89 & 14,32 \\
Olha & 27 & 49 & 55,1 & 13,94 \\
Escola, escolas & 140 & 359 & 39 & 13,91 \\
Não & 394 & 1160 & 33,97 & 13,61 \\
Tendência & 6 & 6 & 100 & 13,53 \\
Exatamente & 6 & 6 & 100 & 13,53 \\
Posso & 25 & 46 & 54,35 & 12,27 \\
Posicionamento, posicionamentos & 7 & 8 & 87,5 & 12,12 \\
\hline
\end{tabular}

Fonte: Dados da pesquisa.

prática de estágio e comentam aspectos associados à construção histórica do curso de Pedagogia (Tabela 4).

Os depoentes do quarto ano apontam a gestão democrática como possibilidade de corresponsabilização, dentro da escola, pelos processos de mudança. Contudo, eles relatam que, ao se depararem com a prática de estágio, encontraram uma realidade diferente.

Rev. Diálogo Educ., Curitiba, v. 11, n. 33, p. 375-396, maio/ago. 2011 
No discurso apareceu isso, mas, na prática, eu não consegui perceber explicitamente essa participação efetiva de todos, de alunos, de professores. Infelizmente, me parece que sim porque a gente foi para a escola entrevistar diretora, coordenadora e por meio dessas entrevistas que eu percebi isso, mas não tenho provas, não sei te dizer ao certo se é realmente assim, mas aparentemente nessa escola específica (Suj. 23, $4^{\circ}$ ano vespertino, sexo feminino).

Assim, a perspectiva de mudanças mediante a gestão participativa parece, ao terem contato com as escolas, distante do que aprendem na universidade, não obstante creiam que essa modalidade de articulação coletiva seja possível.

Outros alunos pontuam que as mudanças que percebem necessárias a partir das discussões feitas na graduação encontram barreiras na realidade e nas dificuldades em sala de aula. Pode-se inferir que aquilo que é encontrado na realidade destoa das expectativas dos futuros professores, conforme se nota pelos discursos subsequentes.

Você também tem que se adaptar, mas eu acho que a maior dificuldade em sala mesmo é lidar com tanta dificuldade emocional, devido a essa questão relacionada à educação e família não formal que o professor tem que atender, tem que se virar. Tem que ser psicólogo, pai, mãe, professor, tem que saber dosar (Suj. 6, $4^{\circ}$ ano vespertino, sexo feminino).

Mas a questão da valorização, não só do governo, mas da sociedade mesmo. Você vê pais brigando com professores, pais que não mandam seus filhos para a escola, eu acho que é isso mesmo, mais reconhecimento, não só do lado financeiro, já caiu na mesmice dizer isso (Suj. 18, 4º ano matutino, sexo feminino).

As mudanças apontadas por tais falas se referem às ampliações da função docente e à desvalorização social. Entretanto, a última manifestação assinala que a necessidade de reconhecimento do professorado não é algo novo, mas que se naturalizou no discurso e parece apresentar uma realidade inquestionável. 
Observa-se que as conclusões sobre a prática do professor nas escolas, a partir das declarações dos licenciandos do quarto ano, se aproximam do discurso da adaptação, adequação às mudanças, em oposição à busca por transformação, assemelhando-se, ainda, aos discursos de docentes em exercício, como revelam estudos recentes nas redes estadual e municipal de ensino de Cuiabá, ao retratarem as representações desse profissional acerca de suas atividades (CÂNDIDO; BATISTA, 2008).

Sobre a participação dos alunos de Pedagogia em mudanças na graduação, esse grupo salienta que seu envolvimento é insuficiente e alguns alegam não participar por falta de implicação pessoal, outros por falta de incentivo da instituição.

Pode-se pensar que essa falta de participação dos acadêmicos do quarto ano parece ser reflexo do momento em que estes se encontram no curso, no qual as questões coletivas e a busca por mudanças dentro da academia dão lugar aos interesses individuais e à busca por colocação no mercado de trabalho. Os estudantes resgatam, ainda, alguns aspectos da história do curso de Pedagogia, especialmente sobre o currículo que foi base na sua faculdade, construído para cumprir a formação de professores em exercício. Assim, ao trazer à tona esses pontos históricos, os alunos retratam a queixa de que houve pouco contato com a prática profissional - como o estágio - dentro de seu curso.

Agora parece que está dentro do currículo que precisaria desde o primeiro ano estar vivenciando mais, até porque, depois destes dez anos, desta formação destes professores que estavam em exercício, mas não tinham o terceiro grau, o pessoal que entrou no curso de Pedagogia é um pessoal mais novo, que não tem o magistério, que nunca deu aula, que escolheram o curso de Pedagogia porque... Até porque o curso de magistério saiu também (Suj. 19, $4^{\mathrm{o}}$ ano matutino, sexo feminino).

Assim, as questões que parecem se encontrar no cerne dos discursos desse grupo aludem a como irão ser professores, mediante a pouca prática profissional encontrada no curso. As ansiedades se encontram em dominar as técnicas de ser um bom professor, mais do que questões de 
cunho coletivo ou teórico. Nota-se que, nesse sentido, os discursos desse grupo se assemelham aos dos demais colegas dos outros anos.

Pode-se dizer que os temas do terceiro e do quarto ano são próximos por tratarem da busca pela prática profissional e da busca por certezas de uma boa aprendizagem profissional ainda dentro da universidade. Tais temas divergem, entretanto, porque, enquanto o terceiro ano salienta suas expectativas em relação ao futuro profissional, as mudanças enxergadas pelos acadêmicos do quarto ano se fazem no confronto com a prática de estágio, que transforma as representações fomentadas pelos enfoques teóricos tratados na universidade.

\section{Considerações finais}

A análise tri-croisé possibilitou um olhar distinto acerca das representações sociais dos licenciandos em Pedagogia, ao separar seus discursos pela variável ano. O software facilitou, por meio dessa ferramenta, a compreensão das especificidades do grupo de alunos de acordo com a série em que se encontravam.

Notou-se que as representações sociais dos alunos de Pedagogia do primeiro ano destacaram os significados atribuídos às mudanças, considerando-as como situações que devem ser buscadas para melhorar e evoluir. Essa busca se mostra por tais alunos como algo pelo qual se deve depreender um esforço individual, sem mencionar articulação coletiva com seus pares, centrada na universidade. Os riscos decorrentes de mudanças não são pontuados pelos alunos do primeiro ano, que parecem amenizar tal possibilidade ao acreditarem em ganhos advindos das mudanças, como a experiência e o conhecimento.

Os licenciandos do segundo ano enfatizaram temáticas relacionadas à dicotomia apresentada previamente entre o aluno que estuda na escola, como elemento passivo na proposição de mudanças, e os universitários, que se mostram ativos e implicados ao buscarem melhorar os seus interesses. Desse modo, a prática correr atrás, em suas próprias palavras, 
é incorporada na universidade, o que revela a função identitária das representações sociais, pois, na medida em que o aluno muda de status ao se tornar universitário, muda também a forma como percebe a si mesmo e as expectativas sociais ao seu redor.

Além disso, os entrevistados intensificam a importância do trabalho do professor nas mudanças educacionais, reforçando assim uma identidade positiva, que legitima a escolha pelo curso e a permanência em tal profissão no futuro.

Os primeiros e segundos anos formam, assim, um bloco de significados próximos, em que as mudanças se mostram possíveis mediante o engajamento individual, ora na vida pessoal (primeiro ano), ora na vida acadêmica (segundo ano).

O terceiro ano tem como discurso específico as expectativas em relação à sua profissão, apresentando as possibilidades de atuação no futuro. Ademais, os estudantes entrevistados refletem acerca das mudanças anunciadas na Pedagogia, por meio da contextualização do curso e da projeção da profissão. Essas projeções revelam, no discurso desse grupo de licenciandos, certo conflito diante do que se é estudado na academia e as expectativas relativas à prática profissional.

Por fim, o grupo do quarto ano assinala as dificuldades encontradas em mudanças nas escolas, enfrentadas por eles na prática de estágio. Também são salientados aspectos históricos do curso de Pedagogia e reforçadas as necessidades de mudanças no curso, especialmente no que se refere ao aumento de contato com a prática durante a formação, refletindo nesse grupo a tensão entre teoria e prática.

Os terceiros e quartos anos formam, desse modo, outro conjunto de significados, no qual há uma transformação das representações sociais construídas nos anos iniciais do curso. Se inicialmente o engajamento pessoal anunciava a concretização de mudanças, nos últimos anos há o conflito e a negação destas.

Percebe-se, por conseguinte, que nos anos finais da graduação em Pedagogia há um rompimento com o discurso da mudança e a negação do conhecimento acadêmico em nome de sua adaptação à realidade do 
mercado de trabalho. Quando esses alunos referem-se ao professor na escola pública, nota-se ainda uma incorporação do discurso acerca da desvalorização e vitimação do professor.

Assim, pode-se pensar na existência de uma imobilização do pensar sobre a realidade do trabalho docente, que se justifica por meio dos discursos, tais como: a teoria aprendida na universidade que se mostra inócua pelos licenciandos; a realidade psicossocial dos alunos; a realidade das condições de trabalho; o baixo status social do trabalho docente.

Nota-se que as representações sociais dos acadêmicos em Pedagogia da UFMT se apresentam segundo o binômio da mudança e da conservação. A mudança é localizada individualmente, na inclusão do sujeito na vida universitária, no nível prático instrumental, especialmente nos primeiros anos do curso. A conservação se apresenta especialmente nos discursos dos terceiros e quartos anos, que ao se depararem com as dificuldades de sua profissão e com a necessidade de implicação nesse movimento incorporam o discurso da desvalorização docente, e o naturalizam, o que favorece a manutenção da representação preexistente.

Esse movimento reflete a preservação identitária do grupo, que, diante do estranhamento gerado pelas incertezas das mudanças, recai sobre a conservação. Além disso, há uma negação da ação propositiva do professor, em função das decisões top-down, assim como do individualismo, que opera na cultura escolar e parece organizar suas representações sociais.

Portanto, observa-se que as representações sociais dos acadêmicos em Pedagogia da UFMT se constituem em um movimento ancorado no engajamento individual diante da sua formação e sobre as necessidades de mudanças na educação, transformando-se em uma queixa imobilizadora, que impede a sua implicação com as mudanças.

\section{Referências}

ARRUDA, A. Mudança e representação social. Temas em Psicologia da SBP, v. 8, n. 3, p. 241-241, 2000. 
BENTO GUTH, F. Representações sociais de licenciandos em ciências biológicas e educação física da UFMT, sobre o futuro do trabalho docente: um estudo sobre razões para ser professor, atividades docentes atuais e futuras, e do que dependerá o trabalho do professor. 2008. 326 f. Dissertação (Mestrado em Educação) - Universidade Federal de Mato Grosso, Cuiabá, 2008.

CÂNDIDO, F; BATISTA, C. M. P. Ouvindo professores. Cuiabá: EdUFMT; FAPEMAT, 2008. (Educação e Psicologia, v. 11, Coordenação Eugênia Coelho Paredes).

JODELET, D. Representações sociais: um domínio em expansão. In: JODELET, D. (Org.). As representações sociais. Tradução Lilian Ulup. Rio de Janeiro: EdUERJ, 2001. p. 17-44.

JODELET, D. Loucuras e representações sociais. Petrópolis: Vozes, 2005.

MORGADO, L. C. Currículo e profissionalidade docente. Porto: Porto Editora, 2005.

MOSCOVICI, S. A representação social da psicanálise. Tradução Álvaro Cabral. Rio de Janeiro: Zahar, 1978.

MOSCOVICI, S. Representações sociais: investigações em psicologia social. Tradução Pedrinho A. Guareschi. Petrópolis: Vozes, 2003.

SILVA, I. A. A linha do tempo e as representações sociais de professores do ensino fundamental acerca da escola em Cuiabá. 2004. 155 f. Dissertação (Mestrado em Educação) - Universidade Federal de Mato Grosso, Cuiabá, 2004.

Recebido: 29/11/2010

Received: 11/29/2010

Aprovado: 04/02/2011

Approved: 02/04/2011

Rev. Diálogo Educ., Curitiba, v. 11, n. 33, p. 375-396, maio/ago. 2011 